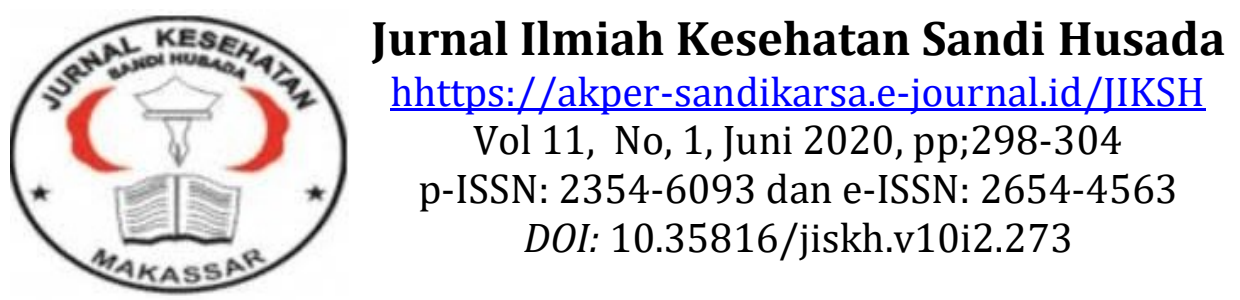

\title{
Perbandingan Stroke Non Hemoragik dengan Gangguan Motorik Pasien Memiliki Faktor Resiko Diabetes Melitus dan Hipertensi
}

Comparison of Non-Hemorrhagic Stroke with Motor Disorders Patients Have Risk Factors for Diabetes Mellitus and Hypertension

Nia Permatasari

Kedokteran Umum, Universitas Malahayati

\section{Artikel info}

\section{Artikel history:}

Received; 10 April 2020

Revised:14 April 2020

Accepted;17 April 2020

\section{Abstrak}

Latar Belakang: Stroke di Indonesia juga mengalami peningkatan prevalensi. Di Indonesia penyakit ini menduduki posisi ketiga setelah jantung dan kanker. Pada tahun 2007, hasil Riset Kesehatan Dasar (Riskesdas) menunjukkan data 8,3 per 1000 penduduk menderita stroke Stroke juga menjadi penyebab kematian utama di hampir semua rumah sakit di Indonesia, yakni sebesar 14,5\%. Tujuan Penelitian: Mengetahui bagaimana Perbandingan Gangguan Motorik Pada Pasien Stroke Non Hemoragik Pasien Dengan Faktor Resiko Diabetes Melitus, Hipertensi, Diabetes Melitus \& Hipertensi Di RSUD Dr. H. Abdul Moeloek Provinsi Lampung Tahun 2018. Metode Penelitian: Rancangan penelitian ini adalah Analitik Deskriftif dengan pendekatan secara Cross sectional. Subjek penelitian ini seluruh pasien Gangguan Motorik Pada Stroke Non Hemoragik Dengan Faktor Resiko Diabetes Melitus, Hipertensi, Diabetes Melitus dan Hipertensi di RSUD Dr. H. Abdul Moeloek Provinsi Lampung.Hasil Penelitian: Sampel penelitian ini 30 pasien. Stroke non hemoragik pada pasien hipertensi sebanyak (92, 6\%), stroke non hemoragik pada pasien diabetes melitus sebanyak (81,5\%), Stroke non hemoragik pada pasien hipertensi dan diabetes melitus sebanyak (74,1\%). Dengan menggunakan uji Kolmogorov-Smirnov $Z$ nilai signifikannya adalah 0,280 $(p=0,280>\alpha=0,05)$ maka Ho diterima. Kesimpulan: Tidak ada perbandingan hipertensi pada stroke non hemoragik dengan gangguan motorik ringan dan sedang di RSUD Dr.H. Abdul Moeloek Provinsi Lampung Tahun 2018.

\section{Abstract.}

Background: Stroke in Indonesia has also increased in prevalence. In Indonesia, this disease ranks third after heart disease and cancer. In 2007, the results of the Basic Health Research (Riskesdas) showed data 8.3 per 1000 population suffered a stroke. Stroke was also the main cause of death in 
almost all hospitals in Indonesia, which amounted to $14.5 \%$.

Purpose: To find out how Comparison of Motor Disorders in

Non-Hemorrhagic Stroke Patients with Risk Factors for

Diabetes Mellitus, Hypertension, Diabetes Mellitus \& Hypertension in RSUD Dr. H. Abdul Moeloek Lampung Province in 2018. Methods: The design of this study was descriptive analytic with cross sectional approach. The subjects of this study were all patients with motor disorders in non-hemorrhagic stroke with risk factors for diabetes mellitus, hypertension, diabetes mellitus and hypertension in RSUD Dr. H. Abdul Moeloek Lampung Province. Result: The study sample was 30 patients. Non-hemorrhagic stroke in hypertensive patients as much as (92.6\%), non-hemorrhagic stroke in patients with diabetes mellitus (81.5\%), nonhemorrhagic stroke in hypertensive patients and diabetes mellitus as much as (74.1\%). By using the KolmogorovSmirnov $Z$ test the significant value is 0.280 ( $p=0.280>\alpha=$ $0.05)$ then Ho is accepted.Conclusion: There is no comparison of hypertension in non-hemorrhagic stroke with mild and moderate motor disturbances at Dr.H. Abdul Moeloek Lampung Province in 2018.

\author{
Keywords: \\ Motor Disorders; \\ Non-Hemorrhagic Stroke; \\ Hypertension; \\ Diabetes Mellitus;
}

Coresponden author:

Email: niapermatasari200@gmail.com

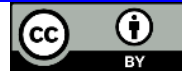

artikel dengan akses terbuka dibawah lisensi CC BY -4.0

\section{Pendahuluan}

Menurut World Health Organization (WHO) stroke merupakan gejala yang didefinisikan suatu gangguan fungsional otak yang terjadi secara mendadak dengan tanda dan gejala klinik baik fokal maupun global yang berlangsung 24 jam atau lebih (Nasution, 2013). Stroke di Indonesia juga mengalami peningkatanprevalensi. Di Indonesia penyakit ini menduduki posisi ketiga setelah jantung dan kanker. Pada tahun 2007, hasil Riset Kesehatan Dasar (Riskesdas) menunjukkan data 8, 3 per 1000 penduduk menderita stroke. Sedangkan pada tahun 2013, terjadi peningkatan yaitu sebesar $12,1 \%$. Stroke juga menjadi penyebab kematian utama di hampir semua rumah sakit di Indonesia, yakni sebesar $14,5 \%$. Jumlah penderita stroke di Indonesia menurut diagnosis tenaga kesehatan (Nakes) pada tahun 2013, diperkirakan sebanyak 1.236.825 orang dari seluruh penderita stroke yang terdata, sebanyak $80 \%$ merupakan jenis stroke iskemik (Wicaksana,eatall, 2017).

Berdasarkan diagnosis tenaga kesehatan maupun diagnosis/gejala, Provinsi Jawa Barat memiliki estimasi jumlah penderita terbanyak yaitu sebanyak 238.001 orang $(7,4 \% 0)$ dan 533.895 orang $(16,6 \%$ ), sedangkan Provinsi Papua Barat memiliki jumlah penderita paling sedikit yaitu sebanyak 2.007 orang $(3,6 \%)$ dan 2.955 orang $(5,3 \%$ ) (Riskesdas, 2013; Pusdatin, 2014). Prevalensi kejadian stroke di Provinsi Lampung berdasarkan diagnosis tenaga kesehatan sebanyak 42.851 orang $(7,7 \% 0)$ dan berdasarkan diagnosis/gejala sebanyak 68.393 orang (12,3\%o) (Pusdatin, 2014). 
Menurut Kabupaten/Kota di Propinsi Lampung, prevalensi kejadian stroke berkisar antara 2,2- 10,5\%o. Kotamadya Bandar Lampung mempunyai prevalensi lebih tinggi dibandingkan dengan Kotamadya/Kabupaten yang ada di Propinsi Lampung, baik berdasarkan diagnosis maupun berdasarkan gejala (Tuntun, 2018). Terdapat beberapa faktor resiko terjadinya stroke non hemoragik, antara lain: usia lanjut, hipertensi, diabetes melitus, penyakit jantung, hiperkolesterolemia, merokok dan kelainan pembuluh darah otak. Pada tahun 2011 WHO memperkirakan sebanyak 20,5 juta jiwa di dunia menderita stroke, dari jumlah tersebut 5,5 juta jiwa telah meninggal dunia. Penyakit darah tinggi atau hipertensi menyumbangkan 17,5 juta kasus stroke di dunia (Nasution, 2013).

Berdasarkan hal tersebut di atas, maka dengan faktor resiko diabetes melitus, hipertensi, diabetes melitus dan hipertensi, peluang untuk terjadinya stroke non hemoragik lebih meningkat. Oleh karena itu untuk membuktikan hal ini, akan dilakukan penelitian mengenai perbandingan stroke non hemoragik dengan gangguan motorik pada pasien yang memiliki faktor resiko diabetes melitus, hipertensi, diabetes melitus \& hipertensi di rsud dr. h abdul moeloek provinsi lampung.

\section{Metode}

Jenis penelitian ini adalah kuantitatif, yaitu penelitian ilmiah yang sistematis terhadap bagian-bagian dan fenomena serta hubungan-hubungannya. Penelitian kuantitatif merupakan definisi, pengukuran data kuantitatif dan statistik objektif melalui perhitungan ilmiah berasal dari sampel orang-orang atau penduduk yang diminta menjawab atas sejumlah pertanyaan tentang survei untuk menentukan frekuensi dan presentase tanggapan mereka. Pada pasien yang terdiagnosa stroke non hemoragik dengan faktor resiko diabetes melitus, hipertensi, diabetes melitus \& hipertensi di RSUD Dr. H Abdul moeloek provinsi lampung. Waktu penelitian akan dilaksanakan dari bulan Mei 2019, dengan data yang di ambil dari rekam medik pada bulan September sampai Desember Tahun 2018. Tempat penelitian ini di RSUD Dr. H. Abdul Moeloek Provinsi Lampung. Rancangan penelitian ini adalah Analitik Deskriftif dengan pendekatan secara Cross sectional. Cross sectional adalah suatu penelitian yang di lakukan pada satu saat atau pada satu periode waktu tertentu.

\section{Hasil Dan Pembahasan}

Tabel 1. Analisis Perbandingan Stroke Non Hemoragik Dengan Gangguan Motorik Pada Pasien Hipertensi di RSUD Dr.H. Abdul Moeloek Provinsi Lampung Tahun 2018. Gangguan Motorik

\begin{tabular}{|c|c|c|c|c|c|c|c|}
\hline \multirow{3}{*}{ Hipertensi } & \multicolumn{4}{|c|}{ Gangguan IMotorlK } & \multirow{2}{*}{\multicolumn{2}{|c|}{ Total }} & \multirow{3}{*}{ P Value } \\
\hline & \multicolumn{2}{|c|}{ Ringan } & \multicolumn{2}{|c|}{ Sedang } & & & \\
\hline & $\mathrm{N}$ & $\%$ & $\mathrm{~N}$ & $\%$ & $\mathrm{~N}$ & $\%$ & \\
\hline $\begin{array}{c}\text { Normal } \\
(\leq 140 / 80 \mathrm{~mm} / \mathrm{Hg})\end{array}$ & 1 & $33,3 \%$ & 2 & $7,4 \%$ & 3 & $10,0 \%$ & 0,280 \\
\hline $\begin{array}{c}\text { Hipertensi } \\
(\geq 140 / 90 \mathrm{~mm} / \mathrm{Hg})\end{array}$ & 2 & $66,7 \%$ & 25 & $92,6 \%$ & 27 & $90,0 \%$ & \\
\hline
\end{tabular}

\begin{tabular}{|c|c|c|c|c|c|c|}
\hline Total & 3 & $100 \%$ & 27 & $100 \%$ & 30 & $100,0 \%$ \\
\hline
\end{tabular}


Tabel 2. Analisis Perbandingan Stroke Non Hemoragik Dengan Gangguan Motorik Pada Pasien Diabetes Melitus di RSUD Dr.H. Abdul Moeloek Provinsi Lampung Tahun 2018.

\begin{tabular}{|c|c|c|c|c|c|c|c|}
\hline \multirow{3}{*}{ Diabetes Melitus } & \multicolumn{4}{|c|}{ Gangguan Motorik } & \multirow{2}{*}{\multicolumn{2}{|c|}{ Total }} & \multirow{3}{*}{$\begin{array}{l}\mathrm{P} \\
\text { Value }\end{array}$} \\
\hline & \multicolumn{2}{|c|}{ Ringan } & \multicolumn{2}{|c|}{ Sedang } & & & \\
\hline & $\mathrm{N}$ & $\%$ & $\mathrm{~N}$ & $\%$ & $\mathrm{~N}$ & $\%$ & \\
\hline $\begin{array}{l}\text { Normal } \\
(\leq 200 \mathrm{~g} / \mathrm{dL})\end{array}$ & 1 & $33,3 \%$ & 5 & $18,5 \%$ & 6 & $20,0 \%$ & 0,501 \\
\hline $\begin{array}{l}\text { Diabetes Melitus } \\
(\geq 200 \mathrm{~g} / \mathrm{dL})\end{array}$ & 2 & $66,7 \%$ & 22 & $81,5 \%$ & 24 & $80,0 \%$ & \\
\hline Total & 3 & $100 \%$ & 27 & $100 \%$ & 30 & $100,0 \%$ & \\
\hline
\end{tabular}

Tabel 3. Analisis Perbandingan Stroke Non Hemoragik Dengan Gangguan Motorik Pada Pasien Hipertensi \& Diabetes Melitus di RSUD Dr.H. Abdul Moeloek Provinsi Lampung Tahun 2018.

Gangguan Motorik

\begin{tabular}{|c|c|c|c|c|c|c|c|}
\hline \multirow{3}{*}{$\begin{array}{l}\text { Hipertensi } \\
\text { Diabetes Melitus }\end{array}$} & \multicolumn{4}{|c|}{ Gangguan Motorik } & \multicolumn{2}{|c|}{ Tetol } & \multirow{3}{*}{$\begin{array}{l}\mathrm{P} \\
\text { Value }\end{array}$} \\
\hline & \multicolumn{2}{|c|}{ Ringan } & \multicolumn{2}{|c|}{ Sedang } & & & \\
\hline & $\mathrm{N}$ & $\%$ & $\mathrm{~N}$ & $\%$ & $\mathrm{~N}$ & $\%$ & \\
\hline Ya & 1 & $33,3 \%$ & 20 & $74,1 \%$ & 21 & $30,0 \%$ & \\
\hline Tidak & 2 & $66,7 \%$ & 7 & $25,9 \%$ & 9 & $70,0 \%$ & 0,207 \\
\hline Total & 3 & $100 \%$ & 27 & $100 \%$ & 30 & $100,0 \%$ & \\
\hline
\end{tabular}

Sumber: data primer diolah 2018

Berdasarkan analisis diketahui bahwa hasil analisis perbandingan Stroke Non Hemoragik dengan Hipertensi \& Diabetes Melitus, terbanyak pada pasien yang memiliki riwayat Hipertensi \& Diabetes Melitus ( $\geq 140 / 90 \mathrm{mmHg}$ dan $\geq 200 \mathrm{~g} / \mathrm{dL}$ ) dengan gangguan motorik sedang sebanyak 20 pasien $(74,1 \%)$. Tabel $2 \times 2$ ini tidak layak untuk di uji ChiSquare karena terdapat 2 nilai Expected Count yang kurang dari 5 ada 50\% jumlah sel. Oleh karena itu uji yang dipakai adalah uji alternatifnya, yaitu uji Kolmogorov-Smirnov Z. Hasil uji statistic menggunakan uji Kolmogorov-Smirnov $Z$ nilai signifikannya adalah 0,207 , karena nilai $p=0,207>\alpha=0,05$, maka Ho diterima artinya Tidak ada perbandingan Hipertensi \& Diabetes Melitus pada penyakit Stroke Non Hemoragik ada penyumbatan di RSUD Dr.H. Abdul Moeloek Provinsi Lampung Tahun 2018.

Berdasarkan hasil pengolahan data mengenai perbandingan Stroke Non Hemoragik dengan faktor resiko Hipertensi, Diabetes Melitus, Hipertensi \& Diabetes Melitus, yang mengalami gangguan motorik sehingga dapat disimpulkan sebagai berikut: Pada hasil penelitian ini seharusnya pasien dengan faktor resiko Hipertensi, Diabetes Melitus, Hipertensi \& Diabetes Melitus yang mengalami kelainan motorik sedang harusnya lebih tinggi dibanding yang hanya memiliki satu faktor resiko. Hal ini disebabkan beberapa faktor diantaranya seperti pengambilan sampel yang tidak melihat onset serangan pasien. Hal tersebut dimaksudkan pada onset akut biasanya dikenal dengan hiperglikemia reaktif.

Hiperglikemia merupakan akibat respon stress sesudah terjadi Stroke. Respon sress ini mengakibatkan peningkatan Katekolamin, Lipolisis, kenaikan kadar Asam Lemak Bebas, dan hal itu merupakan prognosis buruk. Hiperglikemia dapat menyebabkan berkurangnya konsumsi Oksigen otak pasca iskemik dibandingkan pada pasien dengan Normoglikemia. 
Hiperglikemia reaktif akan mempengaruhi proses penyembuhan, memperberat akibat stroke iskemik, dan juga mempercepat rekuren atau kekambuhan Stroke. Keadaan Hiperglikemia juga mempermudah terjadinya edem otak dan meningkatkan angka kematian pasien yang dirawat akibat Stroke (Yaris, 2004).

Berdasarkan analisis diketahui bahwa hasil analisis perbandingan gangguan motorik penyakit Stroke Non Hemoragik dengan penyumbatan terbanyak pada gangguan motorik sedang (2-3) 27 pasien (90\%). Pada penelitian ini didapatkan hasil uji statistik Stroke Non Hemoragik menggunakan uji Kolmogorov-Smirnov $Z$ nilai signifikannya adalah 0,00, karena nilai $p=0,00>\alpha=0,05$, maka Ho diterima artinya Tidak ada perbandingan gangguan motorik pada penyakit stroke non hemoragik ada penyumbatan di RSUD Dr.H. Abdul Moeloek Provinsi Lampung Tahun 2018.

Stroke merupakan kerusakan organ target pada otak yang diakibatkan oleh Hipertensi. Stroke timbul karena perdarahan, tekanan intra kranial yang meninggi, atau akibat embolus yang terlepas dari pembuluh non otak yang terpajan tekanan tinggi. Apabila terjadi peningkatan salah satu dari variabel tersebut yang tidak terkompensasi maka dapat menyebabkan timbulnya hipertensi. Tubuh memiliki sistem yang berfungsi mencegah perubahan tekanan darah secara akut yang disebabkan oleh gangguan sirkulasi dan mempertahankan stabilitas tekanan darah dalam jangka panjang (Dinata,eatall, 2013)

Kegagalan dalam mensuplai darah akan menyebabkan gangguan fungsi bagian otak atau yang terserang atau terjadi kematian sel saraf (nekrosis) dan kejadian inilah yang disebut stroke. Salah satu penyebab meningkatnya kasus penyakit pembuluh darah, seperti jantung dan stroke adalah kurangnya kesadaran masyarakat untuk menerapkan pola gaya hidup sehat (Junaidi, 2011).

Modifikasi pola hidup dengan mematuhi diet merupakan langkah pencegahan yang baik. Pengendalian yang dapat dilakukan untuk menurunkan angka kejadian Hipertensi adalah dengan melakukan program gaya hidup sehat, modifikasi gaya hidup membantu termasuk pengurangan berat badan, pembatasan natrium, diet banyak makan buah, sayuran dan hasil olahan rendah lemak, olahraga teratur, dan tidak berlebihan konsumsi alkohol. Apabila penyakit ini tidak terkontrol, akan menyerang target organ, dan dapat menyebabkan serangan jantung, stroke, gangguan ginjal, serta kebutaan. Dari beberapa penelitian dilaporkan bahwa penyakit hipertensi yang tidak terkontrol dapat menyebabkan peluang tujuh kali lebih besar terkena Stroke (Fitri, 2009).

Diabetes Melitus adalah kondisi dimana terjadi peningkatan insulin dalam darah pada Diabetes Melitus yang dewasa ini semakin meningkat jumlahnya di masyarakat, kondisi tersebut meningkatkan penyerapan jumlah natrium didalam tubuh. Penyerapan natrium akan meningkatkan kadar kalium dalam darah dan akan menyebabkan terstimulasikan sistem saraf simpatik. Hal ini diduga menyebabkan perubahan struktur dalam darah yang mempengaruhi fungsi jantung dan tekanan darah. Masalah vaskular yang timbul dikarenakan diabetes dan diperparah dengan hipertensi, pola makan yang tidak baik serta kurangnya aktivitas fisik. Sehingga diabetes melitus adalah kondisi dimana secara tidak langsung akan mempengaruhi untuk terjadinya Hipertensi (Ramadany, 2013).

Pada penelitian ini Stroke Non Hemoragik pada gangguan motorik dengan ada penyumbatan dan tidak ada penyumbatan didapat hasil usia manula $>65$ tahun dengan penyakit Stroke Non Hemoragik memiliki gangguan motorik sedang (2-3) sedangkan usia manula $>65$ tahun dengan penyakit stroke non hemoragik memiliki gangguan motorik ringan (4-5). Hasil uji statistik menggunakan uji Kolmogorov-Smirnov $Z$ nilai signifikannya adalah 0,00 , karena nilai $p=0,00>\alpha=0,05$. Pengukuran dengan menggunakan gangguan motorik didapatkan Hipertensi $(\geq 140 / 90 \mathrm{mmHg}$ ) pada penyakit stroke non hemoragik 
dengan gangguan motorik sedang (2-3). Pengukuran dengan menggunakan gangguan motorik didapatkan diabetes mellitus tinggi $(\geq 200 \mathrm{~g} / \mathrm{dL})$ pada penyakit stroke non hemoragik. Pengukuran dengan menggunakan gangguan motorik didapatkan hipertensi \& diabetes melitus tinggi ( $\geq 140 / 90 \mathrm{mmHg}$ dan $\geq 200 \mathrm{~g} / \mathrm{dL}$ ) dengan penyakit stroke non hemoragik ada penyumbatan. Pengukuran dengan menggunakan gangguan motorik didapatkan gangguan motorik sedang (2-3) dengan adanya penyumbatan. Hasil uji statistik menggunakan uji Chi-Square nilai signifikasinnya adalah 0,280, karena nilai $\mathrm{p}=0,280>\alpha=0,05$. Kelainan motorik ringan, sedang maupun berat dapat terjadi apabila letak atau lokasinya infark pada jarak atau homonkulus yang mengenai motoriknya.

Hubungan antar variabel dianalisa dengan uji bivariat (x2) dan multivariat (regresi logistik ). Hubungan dinyatakan bermakna bila $\mathrm{p}<0,05$. Jenis kelamin dan umur tidak berkorelasi dengan indeks barthel ( $p>0,05)$. Demikian juga Hipertensi, DM, Dislipidemia dan Perokok tidak berhubungan dengan Indeks Barthel ( $p>0,05)$. Dilakukannya Uji Regresi Logistik mendapatkan hasil konstanta atau tidak signifikan karena $p>0,05$. Hasil analisis multivariat dengan regresi logistik tidak menunjukkan adanya korelasi Jenis kelamin, usia, hipertensi, diabetus melitus, dislipidemia, kebiasaan merokok terhadap pemeriksaan indeks barthel (Caesar K, 2014)

\section{Simpulan Dan Saran}

Berdasarkan analisis maka dapat diambil kesimpulan sebagai berikut:

1. Dari hasil penelitian ini didapatkan gangguan motorik pada pasien stroke non hemoragik dengan faktor resiko Hipertensi, Diabetes Melitus, Hipertensi \& Diabetes Melitus lebih banyak dengan gangguan motorik sedang, dengan yang memiliki faktor resiko Hipertensi atau Diabetes Melitus saja.

2. Distribusi frekuensi Stroke Non Hemoragik dengan gangguan motorik, terbanyak penyumbatan dengan gangguan motorik sedang sebanyak 27 pasien $(90,0 \%)$.

3. Distribusi frekuensi Stroke Non Hemoragik pada pasien Hipertensi dengan gangguan motorik sedang, sebanyak 25 pasien (92, 6\%).

4. Distribusi frekuensi Stroke Non Hemoragik pada pasien Diabetes Melitus dengan gangguan motorik sedang, sebanyak 22 pasien $(81,5 \%)$.

5. Distribusi frekuensi Stroke Non Hemoragik pada pasien Hipertensi \& Diabetes Melitus dengan gangguan motorik sedang, sebanyak 20 pasien $(74,1 \%)$.

Hipertensi, Diabetes Melitus, Hipertensi \& Diabetes Melitus dengan gangguan motorik pada pasien Stroke Non Hemoragik mendapatkan perhatian bagi tenaga medis untuk selalu mengendalikan faktor resiko seperti Hipertensi, Diabetes Melitus, Hipertensi \& Diabetes Melitus. Hasil penelitian ini diharapkan dapat menjadi bahan referensi ilmu pengetahuan khususnya tentang gangguan motorik pada penyakit Stroke Non Hemoragik dengan faktor resiko Hipertensi, Diabetes Melitus. Hipertensi \& Diabetes Melitus. Diharapkan dapat meningkatkan pengetahuan tentang seberapa pentingnya menghindari faktor resiko seperti hipertensi, Diabetes Mllitus, Hipertensi \& Diabetes Melitus sehingga terhindar dari serangan Stroke. 


\section{Daftar Rujukan}

Caesar K. (2014). Hubungan Faktor Risiko Hipertensi Dan Diabetes Mellitus Terhadap Keluaran Motorik Stroke Non Hemoragik[skripsi]. Semarang: Universitas Diponegoro.

Dinata, Safrtita, S. (2013). Gambaran Faktor Risiko dan Tipe Stroke pada Pasien Rawat Inap di Bagian Penyakit Dalam. Jurnal Kesehatan Andalas, 2(3), 58.

Fitri. (2009). Diagnose Enforcement And Treatment Of High Blood Pressure. Jurnal Majority, 4(3), 50.

Junaidi. (2011). STROKE Waspadai Ancamannya (1st ed.). Yogyakarta: C.V Andi Offset.

Nasution. (2013). Stroke Non Hemoragik Pada Laki-Laki Usia 65 Tahun. Jurnal Medula, $1(3), 2-7$.

Pusdatin. Pusdatin. , (2014).

Ramadany, Pujarini, C. (2013). Hubungan Diabetes Melitus Dengan Kejadian Stroke Iskemik. Jurnal Biomedika, 5(2), 12-14.

Tuntun, M. (2018). Difference Hemoglobin Levels, Value Of Hematocrit And Amount Of Erythrocytes On Hemorrhagic Stroke And Non Hemorrhagic Stroke In RSUD Dr.

H. Abdul Moeloek Provinsi Lampung. Jurnal Analis Kesehatan, 7(2), 725.

Wicaksana,Wati, M. (2017). Perbedaan Jenis Kelamin Sebagai Faktor Risiko Terhadap Keluaran Klinis Pasien Stroke Iskemik. Jurnal Kedokteran Diponegoro, 6(2), 656.

Yaris. (2004). Pola Kadar Glukosa Darah Pada Stroke Akut[skripsi]. Universitas Diponegoro. 